\title{
Optimal conditions of acid modification of Bentonite-Like Clay
}

\author{
Natalya Gorbunova ${ }^{1 *}$ and Aleksandr Vezentsev $^{1}$ \\ ${ }^{1}$ Belgorod State National Reasearch University, General Chemistry Department, 308015 Belgorod, Russia
}

\begin{abstract}
The results of mathematical modeling of the bentonite-like clay's process of modifying various concentrations sulfuric acid depending on time the modification process is given in the presented article. As a result, the optimal parameters of this process were determined by the experimental and calculation method.
\end{abstract}

\section{Introduction}

Implacable pollution of water resources occurs in the process of development of industrialization. Therefore, an important stage in human life is access to clean drinking water. One of the main methods of water fine purification is adsorption, it is possible to purify water from heavy metal ions and organic contaminants [1, 2]. Activated carbons are the best-known adsorbents, but they are relatively expensive [3]. Recently, more and more often, finely-dispersed rocks are used to purify water or air. In particular, bentonite-like clays have the best characteristics - the ratio of adsorption capacity to price. Bentonite-like clay containing at least 60 mass. \% montmorillonite, it is an effective adsorbent for heavy metal ions $\mathrm{Cu}^{2+}, \mathrm{Pb}^{2+}, \mathrm{Ni}^{+}$, $\mathrm{Cd}^{2+}[4,5,6]$.

Montmorillonite is a layered hydroaluminosilicate from the smectites group. A distinctive feature of which is the ability to swell the crystal lattice, it consists of two tetrahedral silicon-oxygen layers and the octahedral aluminum-hydroxyl oxygen layer located between them.

It should be noted that when heterovalent isomorphic substitution of $\mathrm{Si}^{4+}$ on $\mathrm{Al}^{3+}$ occurs in the tetrahedral layer or isomorphic substitution of $\mathrm{Al}^{3+}$ on $\mathrm{Mg}^{2+}$ occurs in the octahedral layer, a negative charge arises, which is compensated by the presence of metal cations in the interlayer space. The role of compensating cations may be $\mathrm{Na}^{+}, \mathrm{K}^{+}, \mathrm{Ca}^{2+}, \mathrm{Mg}^{2+}$ or $\mathrm{Al}^{3+}$, it depends on the clay mineral synthesis conditions. The cation exchange capacity in this case is due to non-stoichiometric substitutions in the octahedral or in the tetrahedral layers. Wherein, the ability to cation exchange in some cases can cause excess negative charges on the side faces of crystals or surface silanol groups.

The scheme of montmorillonite crystal lattice is shown in Fig. 1.

Most often, montmorillonite-containing clay is in close interaction with other rocks, which requires its purification from impurities of accessory minerals. An enhance method is used to improve the sorption characteristics of clays, including elutriation followed by sedimentation analysis. In addition, it is preferable to find more active ions hydrogen in the interlayer space of montmorillonite than other elements. The mineral is modified with various solutions of acids and/or salts in order to increase the adsorption efficiency. In this case, an increase in the interplanar spacing $\mathrm{d}(001) a$ from $12 \AA$ to $18 \AA$ (distance $d$ increases from $3 \AA$ to $9 \AA$ ) is achieved, and as a result, the improvement of the mineral adsorption properties, aimed at sorption of harmful substances $[7,8]$.

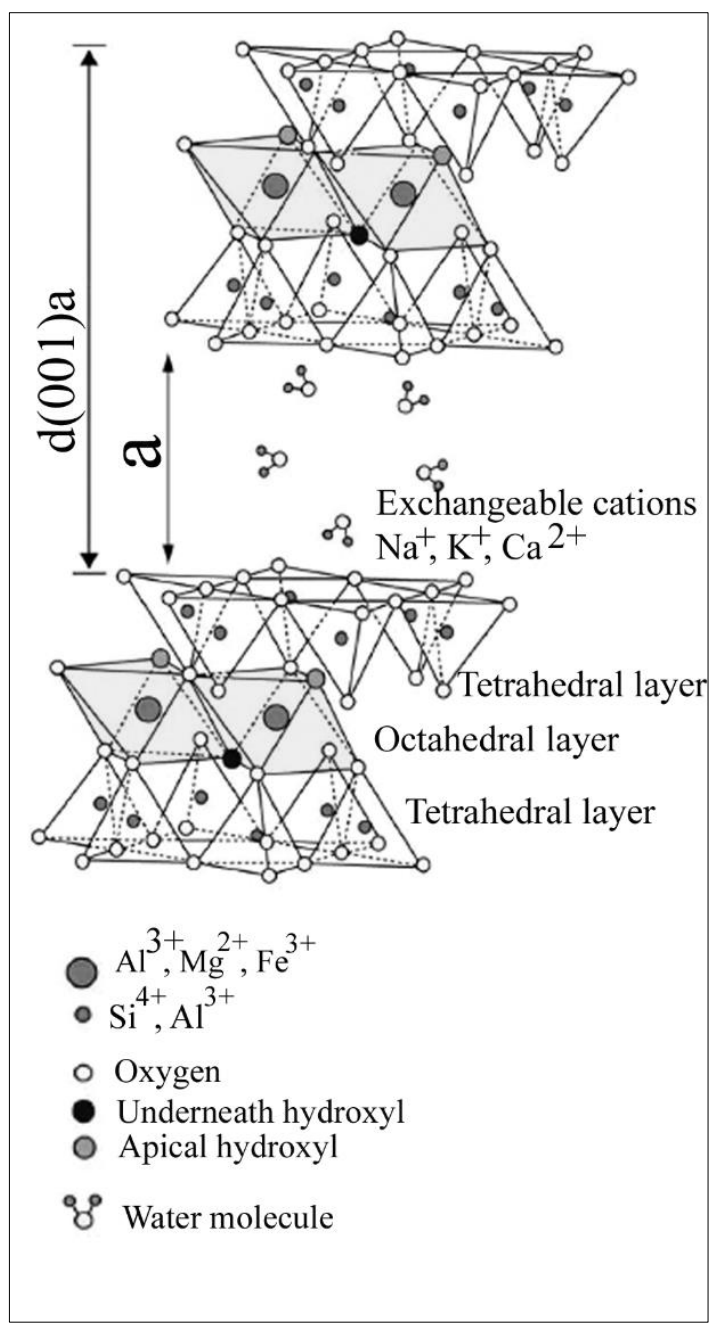

*Corresponding author: natrase@mail.ru 
Fig. 1. The scheme of the crystal lattice of montmorillonite

This clay used in the work does not contain exchange $\mathrm{H}^{+}$and $\mathrm{A}^{3+}$ in its natural form. The $\mathrm{H}^{+}$and $\mathrm{Al}^{3+}$ cations appear as a result of the replacement of mono- and divalent cations of alkali and alkaline earth metals, which occupy exchange positions on the inner surface of clay minerals with hydrogen ions of an activating acid. $\mathrm{H}^{+}$ions not only occupy exchange positions, but, penetrating the structure of montmorillonite, cause partial destruction of it and displace $\mathrm{A}^{3+}$ ions. As with hydrogen ions, aluminum ions occupy exchange positions and create the exchange $\left(\mathrm{H}^{+}\right.$ and $\mathrm{Al}^{3+}$ ) acidity of the adsorbent. In industrial conditions, enumeration of adsorption parameters for energy-efficient cleaning is not applicable.

The most frequently, the erudition and intuition of the researcher determines the duration of the interaction of bentonite and solutions of acids/salts, the ratio of solid and liquid phases, the concentration of acids and salts [9]. Enumeration of modification technological is not applicable in an industrial environment. We carried out mathematical modeling of the cation exchange process when modifying montmorillonite containing clay with sulfuric acid, depending on its concentration and exposure time.

The physicochemical parameters of the acid treatment of bentonite-like clay of the 'Polyana' deposit, Belgorod Region, Russian Federation were determined experimentally. The process of modifying the initial bentonite-like clay was carried out to identify patterns of change in the chemical composition $(\mathrm{Wt} \%)$ of clay material based on montmorillonite [10].

\section{Experiment}

Clay of the 'Polyana' deposit in the Shebekinsky district of the Belgorod region, the content of montmorillonite $40-60 \mathrm{Wt} \%$, was selected as the initial raw material. After elutriation, particles were selected with a size of not more than $10 \mu \mathrm{m}$ by sedimentation method. Then the enhanced product was dried in an oven at a temperature $100 \pm 5{ }^{\circ} \mathrm{C}$ and ground in a porcelain mortar with a porcelain pestle to a particle size of $\leq 50 \mu \mathrm{m}$. After that, the acid treatment of the material 10, 20, $30 \mathrm{Wt} \%$ sulfuric acid at a reaction time of 1 and 6 hours at $97-98{ }^{\circ} \mathrm{C}$ with constant stirring took place. The ratio of solid and liquid phases was 1: 3 (clay: acid). Then the change in the cationic composition of the products of acid treatment was evaluated, namely, an analysis of the content of $\mathrm{Na}^{+}, \mathrm{K}^{+}$, $\mathrm{Ca}^{2+}$ cations in the interplanar spacing of the layered silicate was carried out. It was found that the number of cations tends to a minimum, therefore, these cations are replaced by $\mathrm{H}^{+}$ions. The chemical composition of the test samples was studied using an EDAX energy dispersive analyzer combined with a Quanta 200 3D ion-electron scanning microscope.

The data on the change in cation content in the interlayer space of clay of the Polyana deposit in the Shebekinsky district of the Belgorod region are shown in the table I.

As a result of the experiments, data were obtained that allow us to search for patterns on the change in the cation content in bentonite-like clay, these patterns can be represented in graphical form. But, the data from the tables is not enough to build full-fledged graphs that reflect the laws of composition change; for this reason, the function values presented in the table were interpolated. The authors chose bicubic spline interpolation, as the most adequately reflecting the desired pattern.

Table 1. Change in cation content in montmorillonitecontaining clay

\begin{tabular}{|c|c|c|c|}
\hline \multirow{2}{*}{ Clay process conditions } & \multicolumn{3}{|c|}{$\begin{array}{c}\text { Mass content of the } \\
\text { element }\end{array}$} \\
\hline & $\mathrm{Na}^{+}$ & $\boldsymbol{K}^{+}$ & $\mathrm{Ca}^{2+}$ \\
\hline Enhanced clay & 3.81 & $2 ., 64$ & 3.92 \\
\hline $\begin{array}{c}10 \% \mathrm{H}_{2} \mathrm{SO}_{4} \text { solution } \\
1 \text { hour }\end{array}$ & 3.04 & 2.61 & 2.39 \\
\hline $\begin{array}{c}20 \% \mathrm{H}_{2} \mathrm{SO}_{4} \text { solution } \\
1 \text { hour }\end{array}$ & 1.81 & 2.52 & 1.59 \\
\hline $\begin{array}{c}30 \% \mathrm{H}_{2} \mathrm{SO}_{4} \text { solution } \\
1 \text { hour }\end{array}$ & 1.61 & 2.44 & 1.04 \\
\hline $\begin{array}{c}10 \% \mathrm{H}_{2} \mathrm{SO}_{4} \text { solution } \\
6 \text { hours }\end{array}$ & 0.21 & 1.64 & 0.51 \\
\hline $\begin{array}{c}20 \% \mathrm{H}_{2} \mathrm{SO}_{4} \text { solution } \\
6 \text { hours }\end{array}$ & 0.0 & 1.58 & 0.21 \\
\hline $\begin{array}{c}30 \% \mathrm{H}_{2} \mathrm{SO}_{4} \text { solution } \\
6 \text { hours }\end{array}$ & 0.0 & 1.34 & 0.0 \\
\hline
\end{tabular}

We have adopted the minimum content of exchangeable cations as a criterion for the adsorption capacity of the obtained substance.

It has been established that minerals (except montmorillonite), which may contain $\mathrm{Na}^{+}, \mathrm{Ca}^{2+}$ cations, are absent in the studied clay. $\mathrm{K}^{+}$cations can be included in the interlayer positions of illite, as well as contained in the structure of montmorillonite.

The results of chemical analysis suggest that the $\mathrm{Na}$ form of montmorillonite containing clay, which has greater sorption activity compared to other known forms of bentonite-like clays, is before us. This is due to the fact that $\mathrm{Na}^{+}$ions, being in the exchange positions of the crystal lattice of montmorillonite, are more easily exchanged for ions from the solution.

All necessary calculations are performed in the SciLab environment using special macros.

Three-dimensional graphs of the presented experimental results of the modification of bentonite-like clay with 10, 20,30\% sulfuric acid for 1 hour and 6 hours are shown in Fig. 2.

If the minimum content of exchangeable cations is taken as a criterion for the adsorption capacity of the obtained substance, according to the equation:

$$
P \min =\min \left(P_{\mathrm{i}_{j} j}^{\mathrm{Na}}+P_{\mathrm{i}_{j} j}^{K_{j}}+P_{\mathrm{i}_{j} \mathrm{Ca}}^{\mathrm{Ca}}\right)
$$

where: $P$ is the content of exchangeable cations; $i$ is the row number of the array of values of the exchangeable cations content, showing $\mathrm{Wt} \%$ acid content, array column number showing the reaction time in the acid-clay system.

Using the least squares method to search for functional dependences of changes in the presence of $\mathrm{Na}^{+}, \mathrm{Ca}^{2+}, \mathrm{K}^{+}$ cations at the extreme points of the modification time, we use the following equation as the source [11]:

$$
P=\left(k_{1}-k_{2} \cdot x\right) \cdot\left(k_{3}-x\right)^{2},
$$

where $\mathrm{x}$ is the concentration of acid, $\mathrm{Wt} \%$. 


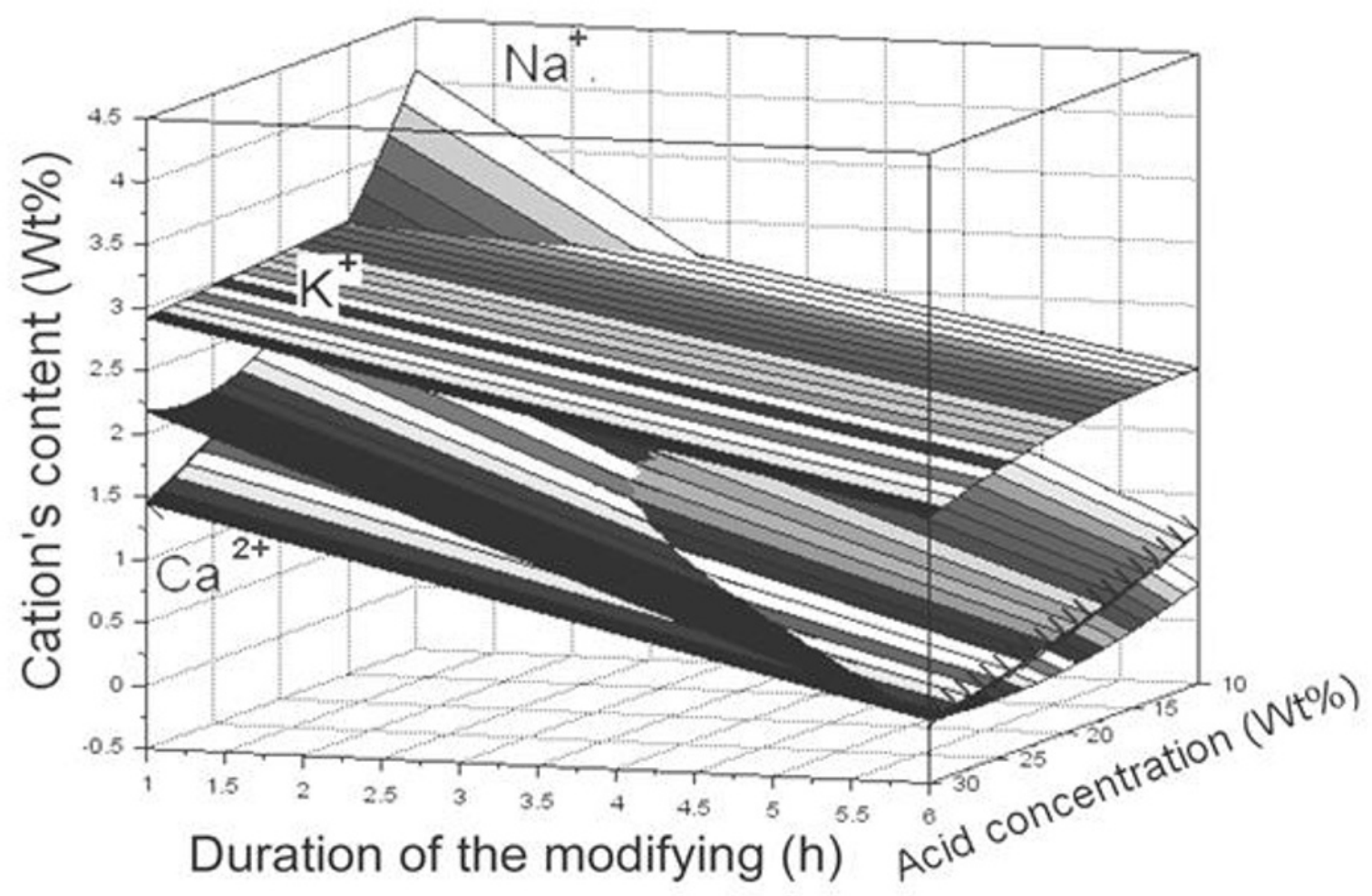

Fig. 2. Dependence of the content of sodium, potassium and calcium cations in bentonite-like clay on acid concentration and processing time

A macro for searching the equation coefficients of the exchange cations of sodium, potassium and calcium was developed by the authors of [10]:

clear

//Duration, hour.

$\mathrm{R}=1: 0.005: 6$

$/ /$ Acid concentration

$\mathrm{AC}=10: 0.2: 50$

// Determination of the sum of the cation content, wt.\% for each element

// Index $2=1 / 2$

// We accept the minimum minimum number of cations, wt.\% equal to 10

Pmin $=100$

for $\mathrm{i}=1$ :length $(\mathrm{AC})$

PNa1(i) $=(0.0002060-0.0000048 * A C(i)) *(-$

137.8602-AC(i) $)^{\wedge} 2$

$\mathrm{PNa} 2(\mathrm{i})=(0.0003062-$

$0.0000142 * \mathrm{AC}(\mathrm{i})) *(11.186818-\mathrm{AC}(\mathrm{i}))^{\wedge} 2$

PK1(i) $=(0.0007318-0.0000129 * A C(i)) *(-$

60.616989-AC(i) $)^{\wedge} 2$

PK2(i) $=\left(0.0007616-0.0000166^{*} \mathrm{AC}(\mathrm{i})\right) *(-$

47.07344-AC(i) $)^{\wedge} 2$

$\mathrm{PCa} 1(\mathrm{i})=(0.0114369$ -

$0.0004024 * \mathrm{AC}(\mathrm{i})) *(11.184091-\mathrm{AC}(\mathrm{i}))^{\wedge} 2$

$\mathrm{PCa} 2(\mathrm{i})=(0.0003435+0.0000090 * \mathrm{AC}(\mathrm{i})) *(-$

99.557432-AC(i) $)^{\wedge} 2$

for $\mathrm{j}=1$ :length $(\mathrm{R})$

// For sodium

if $\mathrm{PNa} 1(\mathrm{i})<=\mathrm{PNa} 2(\mathrm{i})$
$\mathrm{PNa} 1(\mathrm{i})) / \max (\mathrm{R})$

$\mathrm{PNa}(\mathrm{i}, \mathrm{j})=\mathrm{PNa} 1(\mathrm{i})+(0.5+0.005 * \mathrm{j}) *(\mathrm{PNa} 2(\mathrm{i})-$

else

$\mathrm{PNa}(\mathrm{i}, \mathrm{j})=\mathrm{PNa} 1(\mathrm{i})-(0.5+0.005 * \mathrm{j}) *(\mathrm{PNa} 1(\mathrm{i})-$

$\mathrm{PNa} 2(\mathrm{i})) / \max (\mathrm{R})$

end

// For potassium

if PK1(i) $<=$ PK2(i)

$\mathrm{PK} 1(\mathrm{i})) / \max (\mathrm{R})$

$\operatorname{PK}(\mathrm{i}, \mathrm{j})=\mathrm{PK} 1(\mathrm{i})+(0.5+0.005 * \mathrm{j}) *(\mathrm{PK} 2(\mathrm{i})-$

else

PK2(i))/max(R)

$\operatorname{PK}(i, j)=\operatorname{PK} 1(\mathrm{i})-(0.5+0.005 * \mathrm{j}) *(\mathrm{PK} 1(\mathrm{i})-$

end

// For calcium

if $\mathrm{PCa} 1(\mathrm{i})<=\mathrm{PCa} 2(\mathrm{i})$

$\mathrm{PCa} 1(\mathrm{i})) / \max (\mathrm{R})$

$\mathrm{PCa}(\mathrm{i}, \mathrm{j})=\mathrm{PCa} 1(\mathrm{i})+(0.5+0.005 * \mathrm{j}) *(\mathrm{PCa} 2(\mathrm{i})-$

else

$\mathrm{PCa} 2(\mathrm{i})) / \max (\mathrm{R})$

$\mathrm{PCa}(\mathrm{i}, \mathrm{j})=\operatorname{PCa} 1(\mathrm{i})-(0.5+0.005 * \mathrm{j}) *(\mathrm{PCa} 1(\mathrm{i})-$

end

$P(i, j)=P N a(i, j)+P K(i, j)+P C a(i, j)$

if $\mathrm{P}(\mathrm{i}, \mathrm{j})<\mathrm{Pmin}$ then

$\mathrm{Pmin}=\mathrm{P}(\mathrm{i}, \mathrm{j})$

$\mathrm{AC} \_$min $=\mathrm{AC}(\mathrm{i})$

$\min \mathrm{R}=1+0.005 *(\mathrm{j}-1)$

end

end

end

$\operatorname{print}\left(\% \operatorname{io}(2), A C \_\right.$min, min_R,Pmin) 
$\underline{\operatorname{surf}}(\mathrm{R}, \mathrm{AC}, \mathrm{P})$

Thus, Equation for sodium:

The reaction time of acid and clay 1 hour $P^{N a}=(0.0002060+0.0000048 \cdot x)$.

$(137.8602-x)^{2}$

The reaction time of acid and clay 6 hours $P^{N a}=(0.0003062-0.0000142 \cdot x)$.

$(11.186818-x)^{2}$

, (4)

Equation for potassium:

The reaction time of acid and clay 1 hour $P^{K}=(0.0007318-0.0000129 \cdot x)$.

$(-60.616989-x)^{2}$

, (5)

The reaction time of acid and clay 6 hours $P^{K}=(0.0007616-0.0000166 \cdot x)$.

$(-47.07344+x)^{2}$

,(6)

Equation for calcium:

The reaction time of acid and clay 1 hour $P^{C a}=(0.0114369+0.0004024 \cdot x)$.

$(11.184091-x)^{2}$

The reaction time of acid and clay 6 hours $P^{C a}=(0.0003435+0.0000090 \cdot x)$.

$(-99.557432-x)^{2}$

, (8)

\section{Results and discussions}

Fig. 3 shows graphs of the modification's results of the of bentonite-like clay with 10,20,30\% sulfuric acid for 1 hour and 6 hours to compare the experimental and calculated data on the amount of sodium, potassium and calcium cations in bentonite-like clay with modified sulfuric acid depending on the acid concentration and processing time. In these figures, the intersection points of the calculated curve and the curve constructed from experimental data are indicated by the letters A and B. Since the curve reflecting the calculated content of sodium, potassium, and calcium cations in the bentonite-like clay is constructed after interpolation of the experimental data, it is likely that the optimum acid concentration for each particular element is found within a given time ( 1 hour and 6 hours) between these points.

Obviously, the amount of sodium cations decreases with increasing acid concentration. This process is clearly illustrated in Fig. 3-a. The concentration of acid goes by the wayside with an increase in the reaction time of solid and liquid phases, since the values of the content of sodium cations when treated with acid for 6 hours are several times cations is zero when the concentration of 18 wt. $\% \mathrm{H}_{2} \mathrm{SO}_{4}$ is modified and the reaction time is 6 hours. The optimal concentration is achieved when the value is equal to $25 \mathrm{wt} \%$ at a modification time of 1 hour, and $18 \%$ at a reaction time of 6 hours. A further increase in concentration does not lead to a subsequent decrease in the amount of sodium cations. It should be noted that with an increase in acid concentration, partial destruction of the crystal lattice of montmorillonite is possible.

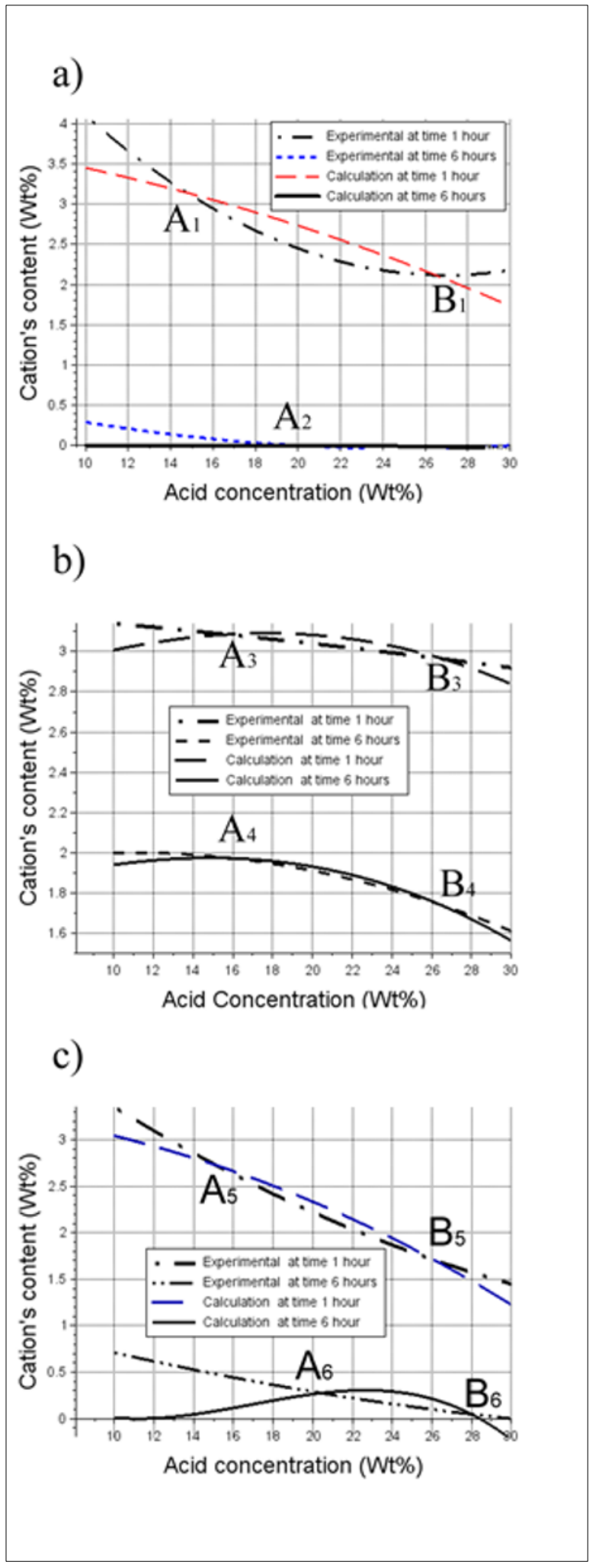

Fig. 3. Dependence of cation content in bentonite-like clay on acid concentration and processing time: a) for sodium, b) for potassium, c) for calcium 
Fig. 3-b shows the congruent graphical dependencies of the graphs of changes in potassium content depending on the acid concentration and duration of treatment. The fact of congruence allows us to estimate the change in the content of potassium cations beyond the limits specified during the experiment. In the case of potassium, the optimal concentration value is $30 \mathrm{wt} \%$ at an interaction time of 1 hour and 6 hours. Since the lowest content of potassium ion-exchange cations is achieved with a modification time of 6 hours, this value of time should be noted as optimal.

Fig. 3-c shows the change in the content of calcium cations. In this case, the content of calcium cations decreases with an increase in the concentration of sulfuric acid. A rapid decrease in calcium ions occurs at a time of interaction of solid and liquid phases for 1 hour, when the reaction time is 6 hours, the nature of the curve is gentler in the decrease direction. It can also be concluded that the range of sulfuric acid concentration, which is probably the optimum for a processing time of 1 hour, lies in the range of $16-28 \mathrm{Wt} \%$, that is, the interval between points $\mathrm{A}_{3}$ and $\mathrm{B}_{3}$. It can also be concluded that the range of effective concentration of sulfuric acid lies in the range of 16-28 $\mathrm{Wt} \%$, similar to the graph of changes in the content of sodium cations. Since when the modification time is 1 hour, the necessary complete removal of calcium cations does not occur, we decided to conduct a process lasting 6 hours under similar conditions, namely at 10, 20, $30 \mathrm{wt} . \%$ sulfuric acid. The optimal value of the concentration of sulfuric acid ranges from 29-30 wt.\% with a duration of modification of 6 hours. It is worth noting that complete removal of calcium from the interplanar distance occurred during the reaction of sulfuric acid and clay, the content of $\mathrm{Ca}^{2+}$ cations became equal to 0.0 when treated with $30 \%$ sulfuric acid with a reaction time of 6 hours. Calcium dihydrosulfate, having a larger molecule size than can fit in the interplanar spacing of montmorillonite, can form on the outer surface of the crystal lattice of minerals that make up bentonite-like clay.

Summing up for each element, we can distinguish the following parameters for effective modification: to completely remove sodium from the interlayer space, it is necessary to treat bentonite-like clay with $18 \mathrm{wt} \%$ sulfuric acid for 6 hours, for the maximum possible removal of potassium $-30 \%$ sulfuric acid for the same 6 hours, for complete removal of calcium - 29\% sulfuric acid for 6 hours. The modifying was tested in the presence of all ionexchange cations in the interlayer space of bentonite-like clay. Therefore, rigid condition - 30 mass. $\%$ sulfuric acid with a reaction time of 6 hours is necessary to completely remove all cations.

Graphical dependences of the change in the content of exchangeable cations $\mathrm{Na}^{+}, \mathrm{K}^{+}, \mathrm{Ca}^{2+}$ in bentonite-like clay depending on the acid concentration and the duration of the modifying were constructed after analysis of the obtained experimental data.

A surface showing the dependence of the total content of exchangeable cations $\mathrm{wt} \%$ on the acid concentration and the duration of the treatment process is presented in Fig. 4.

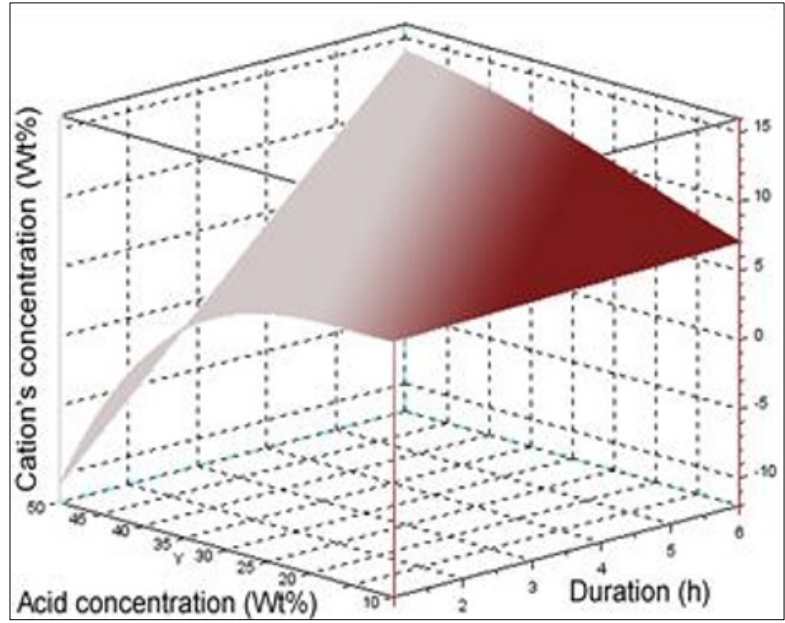

Fig. 4. Dependence of the total content of sodium, potassium and calcium cations in bentonite-like clay on acid concentration and processing time

The optimal design conditions for the modification of the initially specified technological parameters (sulfuric acid concentration of $10,20,30 \mathrm{wt} . \%$ and the duration of the modification of 1 and 6 hours), namely 4 hours 58 minutes and 30 mass. $\% \mathrm{H}_{2} \mathrm{SO}_{4}$, were obtained by performing the necessary calculations in a SciLab environment.

\section{Conclusion}

By the calculation method, we have confirmed that it is optimal to use $30 \mathrm{wt} . \%$ sulfuric acid. And for the first time it was shown that the optimal duration of clay treatment with acid is 4 hours 58 minutes.

Thus, we can safely conclude that the implemented mathematical modeling in the course of chemical experiments gives a clearer picture for the subsequent work.

Studies have made it possible to formulate patterns of changes in the content of various elements cations depending on the concentration of acid and the reaction time in the acid-clay system. The optimal parameters for modifying the starting material with sulfuric acid were revealed. The optimal calculated modification parameters are as follows: $30 \%$ sulfuric acid concentration and modification time 4 hours 58 minutes.

Using the SciLab application, in accordance with the recommendations set forth in [12], it was possible to develop a set of software procedures for processing experimental data and obtaining functional dependencies describing the found patterns. If you expand the scope of the study or conduct data processing of any other experiments, these procedures will also reduce the processing time of the results. When obtaining functional dependencies, the general equation of a quadratic function was used, but this does not exclude its replacement, by any other.

Thus, the automation of calculations for the processing of experimental data not only made it possible to find functional dependencies with the best approximation, but also made it possible to study many 
options for a short period of time with respect to the duration of the experiments.

\section{References}

1. L.Yan, B.Wen', G. Owens, Journal of Hazardous Materials, 156, pp. 499-508, (2008)

2. N.M. Gorbunova, A.I. Vesentsev, International Scientific and Technical Conference 'Innovative Ways to Solve Actual Problems of Environmental Management and Environmental Protection', 4-8 June 2018, Alushta, Russia, (2018)

3. A.I. Vezentsev, E.V. Kormosh, L.F. Peristaya, A.V. Shamshurov, R.A. Cherkasov, J. Engineering and Applied Sciences, 9, 11, P. 2358-2366, (2014)

4. A.V. Sharapova The treatment of wastewater from heavy metals under the influence of ultrasound and the disposal of anti-icing fluids using natural sorbents: inaugural dissertation Candidate of chemical sciences, Ulyanovsk, P.114, (2015)

5. A.I. Vesentsev, S.V. Korolkova, N.A. Volovicheva, S.V. Kudiakova, Sorbtsionnye i

Khromatograficheskie Protsessy, 9 (6): pp. 830-834. (in Russian), (2009)

6. N.A. Volovicheva, A.I. Vesentsev, S.V. Korolkova, N.F. Ponomareva, Water: chemistry and ecology, 9, pp. 60-66, (in Russian), (2011)
7. E.S. Klimov, M.V. Buzayeva, Natural sorbents and complexons in sewage treatment, Ulyanovsk, ULGTU, p. 201, (2011)

8. N.G. Vasil'ev, V.V. Goncharuk, Synthesis and physical and chemical properties of inorganic and carbon sorbents, Kiev, Naukova dumka, pp.58-72. (1986)

9. S.A. Semenov, Educational-methodical manual, Moscow, IPC MITHT, P. 93, (2001)

10. E.V. Barannikova, A.I. Vesentsev, Belgorod State University Scientific bulletin. natural sciences. Belgorod State National Research University Belgorod Publishing House, pp.50-52, (in Russian), (2005)

11. Certificate of the Russian Federation No.2019667682 on state registration of a computer program, 26.12.2019 г. M.S. Chepchurov,, I.A. Teterina, A.I. Vesentsev, N.M. Gorbunova// Software for processing experimental data with the search for the optimal composition of chemical mixtures.

12. Sandeep Nagar. Working with Scilab. November 2017.DOI: 10.1007/978-1-4842-3192-0_2 